\title{
ANÁLISE DE ASPECTOS DE NATUREZA DA CIÊNCIA EXPRESSOS POR UMA PROFESSORA EM FORMAÇÃO INICIAL NO CONTEXTO DE UMA DISCIPLINA DE HISTÓRIA DA QUÍMICA
}

\author{
Marcondes Medeiros de Lima' \\ - Stefannie de Sá lbraim² \\ - Monique Santos ${ }^{2}$ \\ https://orcid.org/0000-0001-5420-5173 \\ https://orcid.org/0000-0001-5724-993X \\ https://orcid.org/0000-0001-6042-0312
}

\section{RESUMO:}

Pesquisadores têm ressaltado a necessidade de professores desenvolverem seus conhecimentos de Natureza da Ciência. Diante disso, investigamos as visões sobre Ciências de uma professora em formação inicial, para tal, identificamos e discutimos aspectos de Natureza da Ciência que foram expressos por ela em um ambiente de ensino-aprendizagem de história da química envolvendo explicitamente discussões sobre Ciências. Baseado em notas de campo e no portfólio redigido pela professora em formação, identificamos, utilizando o MoCEC v.2, a expressão de 23 aspectos de Natureza da Ciência relacionados ao contexto dos casos históricos discutidos na disciplina. Por fim, enfatizamos a necessidade de discussões sobre Ciências e sobre história da química permearem a formação inicial, visando o desenvolvimento e mobilização de conhecimentos pedagógicos de conteúdo, e discutimos as potencialidades e limitações do uso do MoCEC v.2 como ferramenta de análise.

\section{ANALYSIS OF ASPECTS OF NATURE OF SCIENCE EXPRESSED BY A TEACHER IN INITIAL TRAINING IN THE CONTEXT OF A CHEMISTRY HISTORY DISCIPLINE}

\begin{abstract}
:
Researchers have emphasized the need for teachers to develop their knowledge of nature of science. Therefore, we investigated the views about science of a pre-service teacher, for such, we identified and discussed aspects of nature of science that were expressed by her in a teaching-learning environment of History of Chemistry explicitly involving discussions about science. Based on field notes and the portfolio written by the pre-service teachers, we identified, from MoSSE v.2, the expression of 23 aspects of nature of science related to the context of the historical cases discussed in the discipline. Finally, we emphasize the need for discussions about science and about History of Chemistry to permeate pre-service teacher education, aiming at the development and mobilization of pedagogical content knowledge, and we discuss the potentials and limitations of using MoSSE v.2 as an analysis tool.
\end{abstract}

Palavra-chave:

Natureza da Ciência;

Formação Inicial;

História da Química.

\section{Keywords:}

Nature of science;

Pre-service Teacher

Education; History of

Chemistry.

\footnotetext{
1 Universidade de Brasília, Instituto de Química, Brasília, DF, Brasil

2 Universidade Federal de Minas Gerais, Belo Horizonte, MG, Brasil.
} 


\section{ANÁLISIS DE ASPECTOS DE NATURALEZA DE LA CIENCIA EXPRESADOS POR UNA PROFESORA EN FORMACIÓN INICIAL EN EL CONTEXTO DE UNA DISCIPLINA DE HISTORIA DE LA QUÍMICA}

\section{RESUMEN:}

Los investigadores han enfatizado la necesidad de que los profesores desarrollen sus conoci-

Palabras clave:

Naturaleza de la Ciencia;

Formación Docente

Inicial; Historia de la

Química.

\section{CONSIDERAÇÕES INICIAIS}

Os propósitos para o ensino de Ciências são guiados pelas demandas da sociedade em determinados contextos (Carvalho, 2013). Assim, o fato de as questóes científicas e tecnológicas estarem cada vez mais presentes em nossa sociedade tem destacado a importância de os alunos aprenderem sobre os processos de construção, divulgação e legitimação envolvidos na produção de conhecimento científico.

Nesse sentido, nas últimas décadas, diversos pesquisadores (por exemplo, Moura, Camel, \& Guerra, 2020; Osborne \& Dillon, 2010) têm enfatizado a necessidade de incluir discussóes sobre Natureza da Ciência $(\mathrm{NdC})^{1}$ na área de Ensino de Ciências, isto é, de introduzir discussões sobre as formas de produção de conhecimento científico, a maneira como os cientistas trabalham e as relações entre sociedade e Ciência. Sendo assim, espera-se que os alunos possam aprender sobre Ciências, de forma que mobilizem e/ou desenvolvam capacidades para refletirem criticamente sobre assuntos sociais que são permeados pela Ciência (Allchin, 2013).

Diante disso, destacamos que a discussão sobre $\mathrm{NdC}$ nas salas de aulas está condicionada aos conhecimentos dos professores sobre Ciências, uma vez que um professor não pode ensinar algo que ele desconheça (Shulman, 1986). Pesquisadores que têm investigado as visões sobre Ciências de professores (por exemplo, Guerra-Ramos, 2012; Hanuscin, 2013; Lederman, 2007) ressaltam que muitos apresentam visóes inadequadas.

Guerra-Ramos (2012), por exemplo, identifica visões de professores e discute como elas impactam o ensino planejado e conduzido por eles. Ela destaca que o fato de professores conceberem a Ciência como linear, universal e desprendida de concepçôes e interpretaçôes teóricas, implica em um ensino de Ciências baseado em procedimentos simples e diretivos para a construção do conhecimento, independente do objetivo de investigação e da área de concentração do estudo. Deste modo, professores acabam contribuindo para que seus alunos apresentem uma visão ateórica e linear sobre Ciências (Gil Pérez, Montoro, Alis, Cachapuz, \& Praia, 2001).

Salientamos que, em muitos casos, as visóes inadequadas sobre Ciências de professores resultam em dificuldades para ensinar Ciências de forma mais autêntica, isto é, envolvendo as diversas práticas científicas, oportunidades de avaliarem criticamente as ideias dos colegas etc. (Osborne \& Dillon, 2010). Entretanto, 
durante a formação inicial, geralmente são poucas as oportunidades vivenciadas por licenciandos de participar de discussões sobre $\mathrm{NdC}$, de aprender os conceitos científicos a partir de seus contextos de produção, entre outras ações que podem possibilitar a aprendizagem sobre Ciências (Justi \& Mendonça, 2016; Marques, 2015). Assim, quando formados, professores tendem a reproduzir o modelo de ensino de Ciências vivenciado.

Considerando a necessidade de incluir discussóes sobre Ciências em cursos de formação de professores, alguns autores têm se filiado à linha de ensino baseada na lista de princípios de $\mathrm{NdC}$ (por exemplo, Hanuscin, Akerson, \& Phillipson-Mower, 2016), amplamente divulgada por Lederman e colaboradores (Lederman, 2007; Lederman, Abd-Al-Khalick, Bell, \& Schwartz, 2002). Assim, tais estudos têm focado apenas nas ideias de professores relacionadas aos princípios explicitados na lista, a saber: o conhecimento científico é provisório, tem caráter empírico, é norteado por teorias, é produto de inferência, criatividade e imaginação humanas, e é influenciado pelo contexto cultural e social; existem diferenças entre observação e inferência, e entre teorias científicas e leis.

Essa visão de ensino baseada em listas de princípios tem recebido críticas, por exemplo, por não considerar a existência e as particularidades das diversas Ciências (Irzik \& Nola, 2011; Matthews, 2012) e por pouco contribuir para o entendimento das questóes presentes na sociedade que envolvem Ciência (Allchin, 2011, 2013).

Apostando em uma visão alternativa à de listas de princípios, pesquisadores (por exemplo, Allchin, 2013; Erduran \& Dagher, 2014; Justi \& Erduran, 2015; Matthews, 2012) têm defendido que o ensino de NdC não deve ser declarativo, mas sim contextualizado e integrado respeitando a complexidade das atividades científicas, ou a partir das características semelhantes entre as Ciências (por exemplo, Erduran \& Dagher, 2014).

Nesse sentido, Allchin, Anderson e Nielsen (2014) recomendam o trabalho com atividades investigativas e com estudos de casos contemporâneos e/ou históricos. Neste artigo, focamos no uso de casos históricos, pois o estudo apresentado ocorreu no âmbito de uma disciplina de História da Química (HQ). Segundo Allchin (2013), casos históricos são aqueles que envolvem o engajamento dos alunos com questôes históricas. Essas questóes devem ser analisadas não a partir de conhecimentos que temos hoje, mas à luz de conhecimentos que eram aceitos no contexto histórico relevante à questão analisada, de maneira a compreender como as ideias foram evoluindo ao longo do tempo.

A introdução de elementos relacionados à História da Ciência no ensino sobre Ciências tem sido sinalizada em diversos trabalhos presentes na literatura (por exemplo, Allchin et al., 2014; Justi \& Mendonça, 2016; Martins, 2006; Oki \& Moradillo, 2008). De forma geral, os autores apontam que a inserção de História da Ciência pode: (i) auxiliar no entendimento de como ideais se desenvolvem no decorrer do tempo; (ii) possibilitar discutir como dados são entendidos e teorias são elaboradas; (iii) contribuir para a compreensão de como controvérsias científicas são resolvidas; (iv) favorecer discussôes sobre as influências de contextos sociais no meio científico; e (v) proporcionar discussóes sobre o papel das mulheres no desenvolvimento das Ciências. Assim, essas discussões podem contribuir para que alunos construam uma visão mais ampla sobre Ciências, aprendendo não apenas sobre seus produtos, os conhecimentos científicos, mas também sobre seus processos de construção, divulgação e legitimação (Matthews, 2012).

A fim de contribuir para as discussões sobre $\mathrm{NdC}$ nos cursos de formação de professores e buscando fomentar discussóes sobre a ampliação dos conhecimentos de $\mathrm{NdC}$ de professores em formação inicial, as contribuições do contexto de ensino-aprendizagem de História da Química e sobre como analisar as ideias sobre Ciências expressas em contexto de ensino, buscamos responder: Quais aspectos relacionados à Natureza da Ciência são expressos por um professor de Química em formação inicial ao longo de uma disciplina de História da Química? Como aspectos relacionados à Natureza da Ciência são expressos por um professor de Química em formação inicial a partir do contexto de ensino-aprendizagem de História da Química? 


\section{ASPECTOS METODOLÓGICOS}

Este estudo se alinha aos princípios da pesquisa qualitativa (Merriam, 1988), porque nos preocupamos em compreender aspectos que são expressos por meio de reflexões, indagações, apreciaçóes críticas, entre outros. Além disso, expressamos nossos resultados por meio de descrições e citaçôes dos dados coletados no ambiente de pesquisa: uma turma constituída por $27^{2}$ professores de Química em formação inicial (PQFI) matriculados em uma disciplina de História da Química.

Especificamente, realizamos um estudo de caso (Yin, 2001) porque investigamos o portfólio de uma das PQFI desta turma, Ana. ${ }^{3}$ Portanto, esse estudo é limitado temporalmente e nos possibilitou identificar quais os aspectos de $\mathrm{NdC}$ são mais marcantes e característicos no portfólio de Ana e como esses aspectos são expressos por ela. Optamos por analisar o portfólio de Ana porque ela demonstrou comprometimento com a qualidade de seu trabalho, e participou ativamente dos debates em sala de aula. Além disso, em outros momentos da formação inicial, ela cursou disciplinas que discutiam sobre o ensino de Química, como Práticas de Ensino de Química, Didática da Química e Fundamentos de Ensino de Química.

\section{CONTEXTO DE COLETA DE DADOS}

O presente estudo faz parte de um projeto de pesquisa mais amplo, que visa analisar as visões sobre Ciências de professores em formação inicial no contexto de ensino-aprendizagem de HQ.

A coleta de dados foi realizada no 1o semestre de 2019 em uma disciplina de HQ de uma universidade pública federal, na qual ocorreram encontros semanais com duração de 100 minutos cada. De forma geral, a disciplina abordou discussóes de elementos relacionados à HQ explicitando aspectos como os procedimentos experimentais; os processos de tentativa e erro relacionados à produção de conhecimento científico; o papel das mulheres nas Ciências; as reflexões sobre as contribuiçóes científico-tecnológicas; o reconhecimento do papel dos pesquisadores envolvidos; e as relaçôes da Ciência com a sociedade, cultura, economia, política. Desta maneira, os PQFI tiveram oportunidades de refletir sobre como o conhecimento científico foi se desenvolvendo em momentos históricos específicos e as influências dos outros contextos (por exemplo, cultural, econômico e político) na produção científica. Além disso, foram realizadas discussôes sobre como trabalhar com HQ na Educação Básica.

$\mathrm{Na}$ ocasião, o primeiro autor deste artigo atuou como monitor da disciplina, acompanhando todos os encontros presenciais e registrando em notas de campo suas observações. Além disso, coletamos o portfólio de Ana. Especificamente, o portfólio foi elaborado a partir da participação em oito atividades referente aos elementos relacionados à $\mathrm{HQ}$ discutidos em sala de aula e ao material de leitura disponibilizado pela professora formadora. De forma geral, em cada atividade os PQFI deveriam apresentar e justificar quais elementos da aula anterior e dos textos eles consideravam importantes, apresentar suas reflexôes, indagaçóes e críticas relativas ao seu entendimento sobre Ciências. Na Figura 1, apresentamos os elementos relacionados à HQ, aos materiais básicos, que deveriam ser consultados pelos licenciandos e aos materiais complementares - textos ou vídeos disponibilizados pela professora que seriam consultados dependendo do interesse dos alunos. 
Figura 1. Elementos relacionados à História da Química discutidos em sala de aula e materiais utilizados ao longo da disciplina de História da Química.

\begin{tabular}{|c|c|c|c|}
\hline Atividade & $\begin{array}{l}\text { Elementos relacionados à História da } \\
\text { Química discutidos em sala de aula }\end{array}$ & $\begin{array}{l}\text { Material(is) } \\
\text { básico(s) }\end{array}$ & $\begin{array}{l}\text { Materiais } \\
\text { complementares }\end{array}$ \\
\hline 1 & $\begin{array}{l}\text { Discussões sobre alquimia, abordando a } \\
\text { existência de outras visões para além da europeia } \\
\text { e o desenvolvimento de procedimentos técnicos } \\
\text { nesse período. }\end{array}$ & $\begin{array}{l}\text { Alfonso-Goldfarb } \\
\text { (1987a) }\end{array}$ & $\begin{array}{l}\text { Não foram } \\
\text { disponibilizados. }\end{array}$ \\
\hline 2 & $\begin{array}{l}\text { Discussões sobre trabalhos de Robert Boyle, } \\
\text { abordando o contexto social da época e os } \\
\text { esforços empreendidos pelos cientistas para a } \\
\text { constituição de uma área de conhecimento. }\end{array}$ & $\begin{array}{l}\text { Alfonso-Goldfarb, } \\
\text { Ferraz, Beltran e } \\
\text { Porto (2016) }\end{array}$ & $\begin{array}{l}\text { Alfonso-Goldfarb (1987b) } \\
\text { Anunciação, Neto e } \\
\text { Moradillo (2014) }\end{array}$ \\
\hline 3 & $\begin{array}{l}\text { Discussão sobre controvérsia envolvendo a } \\
\text { autoria da "descoberta" do oxigênio, abordando } \\
\text { as contribuições de Scheele, Priestley e Lavoisier. }\end{array}$ & $\begin{array}{l}\text { Vidal, Chelone e } \\
\text { Porto (2007) } \\
\text { Filgueiras (1995) }\end{array}$ & $\begin{array}{l}\text { Não foram } \\
\text { disponibilizados. }\end{array}$ \\
\hline 4 & $\begin{array}{l}\text { Discussões sobre trabalhos de Dalton com } \\
\text { relação à constituição da matéria, a existência de } \\
\text { controvérsias na Ciência e as contribuições de } \\
\text { novas evidências para dar suporte aos modelos } \\
\text { teóricos existentes. } \\
\text { Discussão sobre o contexto da descoberta de } \\
\text { raios catódicos, a proposição do modelo atômico } \\
\text { de Thomson, as contribuições das discussões } \\
\text { entre os pares e o papel das analogias na Ciência. }\end{array}$ & $\begin{array}{l}\text { Oki (2009) } \\
\text { Lopes e Martins } \\
\text { (2009) }\end{array}$ & $\begin{array}{l}\text { Leal (2001) } \\
\text { Chagas (2011) } \\
\text { Bortolotto et al. (2012) } \\
\text { Lopes (2009) } \\
\text { Carvalho (2010) }\end{array}$ \\
\hline 5 & $\begin{array}{l}\text { Contexto da proposição da existência dos raios } \\
X \text { e trabalhos de Becquerel, debatendo sobre } \\
\text { a credibilidade na comunidade científica e a } \\
\text { influência das crenças e modelos teóricos na } \\
\text { interpretação dos fenômenos investigados. }\end{array}$ & Martins (1990) & $\begin{array}{l}\text { Martins (1998) } \\
\text { Martins (2004) }\end{array}$ \\
\hline 6 e 7 & $\begin{array}{l}\text { Discussões sobre os trabalhos e a vida de } \\
\text { Marie Curie, abordando os desafios impostos } \\
\text { à cientista pela sociedade da época, as } \\
\text { características psicológicas da cientista e os } \\
\text { problemas enfrentados pelos cientistas frente } \\
\text { ao estudo de um novo fenômeno. }\end{array}$ & Noëlle (2016) & $\begin{array}{l}\text { Leroy (1943) } \\
\text { Pugliese (2007) }\end{array}$ \\
\hline 8 & $\begin{array}{l}\text { Propostas de ensino sobre a inserção de HQ e de } \\
\text { aspectos de NdC voltadas para a Educação Básica }\end{array}$ & \multicolumn{2}{|c|}{ Não foram disponibilizados. } \\
\hline
\end{tabular}

\section{REFERENCIAL TEÓRICO-METODOLÓGICO}

Como ferramenta de análise de dados, utilizamos a segunda versão do Modelo de Ciências para o Ensino de Ciências (MoCEC v.2), que foi proposto por Santos, Maia e Justi (2020). Em linhas gerais, o MoCEC v. 2 possibilita uma visão holística da Ciência, além de facilitar a articulação entre aspectos de $\mathrm{NdC}$, visto que ele considera que a Ciência é ampla e constituída de atividades complexas, podendo ser analisada a partir de diversas áreas de conhecimento.

O MoCEC v.2 retrata diferentes áreas de conhecimento como: (i) Filosofia da Ciência (FC), que investiga o que é Ciência e qual a sua importância; (ii) Psicologia da Ciência (PC), que busca entender o comportamento e os processos mentais do cientista; (iii) Antropologia da Ciência (AC), que está relacionada ao estudo da relação entre o ser humano, com o conhecimento científico; (iv) Sociologia da Ciência (SC), que estuda a Ciência como uma prática social; (v) Economia da Ciência (EC), que investiga a transformação do 
conhecimento científico em mercadoria; e (vi) História da Ciência (HC), que estuda as transformaçóes das ideias científicas e a sua produção ao longo do tempo. Os aspectos de $\mathrm{NdC}$ relacionados a cada uma das áreas mencionadas, assim como a descrição de cada um deles são apresentados na Figura 2.

Figura 2. Caracterização dos aspectos de NdC relacionados às áreas de conhecimento adaptada de Santos, Maia e Justi (2020, p. 595-601) (continua)

\begin{tabular}{|c|c|c|}
\hline $\begin{array}{c}\text { Área de } \\
\text { conhecimento }\end{array}$ & Aspecto de NdC & Caracterização do aspecto de NdC \\
\hline \multirow{3}{*}{$\begin{array}{l}\text { Filosofia da } \\
\text { Ciência }\end{array}$} & Epistemologia & $\begin{array}{l}\text { Reflexão do todo, ou seja, em torno da natureza, objetivos, valores, critérios, } \\
\text { processos e práticas científicas e/ou epistêmicas. Assim, é um aspecto } \\
\text { que possibilita reflexões sobre os limites e alcances da construção do } \\
\text { conhecimento científico. }\end{array}$ \\
\hline & Ética & $\begin{array}{l}\text { Valores éticos e morais que norteiam as práticas científicas e/ou epistêmicas, } \\
\text { ou que subsidiam as decisões tomadas na respectiva área. }\end{array}$ \\
\hline & Lógica & $\begin{array}{l}\text { Maneira de pensar e raciocínios relacionados à construção do conhecimento } \\
\text { científico. }\end{array}$ \\
\hline \multirow{13}{*}{$\begin{array}{l}\text { Psicologia da } \\
\text { Ciência }\end{array}$} & Complexidade & $\begin{array}{l}\text { Como, durante os processos de produção e uso do conhecimento científico, } \\
\text { um cientista pode ter dificuldades para compreender alguma parte devido à } \\
\text { sua complexidade. }\end{array}$ \\
\hline & Criatividade & $\begin{array}{l}\text { Capacidade que um cientista possui para elaborar, produzir e/ou inventar algo } \\
\text { novo, bem como inovar a partir de algo que já exista, durante os processos de } \\
\text { produção e uso do conhecimento científico. }\end{array}$ \\
\hline & Falibilidade & $\begin{array}{l}\text { Como cada cientista identifica e lida com erros durante o processo de } \\
\text { produção e uso do conhecimento científico. }\end{array}$ \\
\hline & Incerteza & $\begin{array}{l}\text { Como cada cientista lida com as incertezas, }{ }^{4} \text { mais precisamente como ele } \\
\text { toma consciência, se posiciona e, quando possível ou necessário, toma } \\
\text { decisões frente a elas. }\end{array}$ \\
\hline & $\begin{array}{l}\text { Influência } \\
\text { motivacional }\end{array}$ & $\begin{array}{l}\text { Influências que as motivações intrínsecas e/ou extrínsecas de um cientista } \\
\text { podem sofrer e/ou exercer nos processos de produção e uso do conhecimento } \\
\text { científico. }\end{array}$ \\
\hline & Inteligência & $\begin{array}{l}\text { Características intelectuais de um cientista relacionadas a como ele } \\
\text { compreende, relaciona e faz escolhas relacionadas a determinado } \\
\text { conhecimento científico durante os processos de produção e uso dele, de } \\
\text { forma que seja possível pensar no cientista com inteligência "regular", isto é, } \\
\text { que não tem uma inteligência fora do padrão (é um gênio). }\end{array}$ \\
\hline & Limitação & $\begin{array}{l}\text { Como, devido a fatores internos e/ou externos, um cientista pode vivenciar } \\
\text { dificuldades, ou mesmo se encontrar impossibilitado de dar continuidade ao } \\
\text { processo de produção e uso de determinado conhecimento científico. }\end{array}$ \\
\hline & $\begin{array}{l}\text { Não linearidade do } \\
\text { pensamento }\end{array}$ & $\begin{array}{l}\text { Como o pensamento de um cientista não se modifica linearmente ao longo } \\
\text { dos processos de produção e uso do conhecimento científico. }\end{array}$ \\
\hline & Objetividade & $\begin{array}{l}\text { Como um cientista pode pensar e agir de maneira direta, ou seja, ser focado } \\
\text { em uma meta, durante os processos de produção e uso do conhecimento } \\
\text { científico. }\end{array}$ \\
\hline & Personalidade & $\begin{array}{l}\text { Características individuais de um cientista }{ }^{5} \text { que podem explicar seu } \\
\text { comportamento em determinada situação ao longo dos processos de } \\
\text { produção e uso do conhecimento científico. }\end{array}$ \\
\hline & Racionalidade & $\begin{array}{l}\text { Como um cientista pode pensar e agir em conformidade com a razão, isto é, } \\
\text { como ele pode relacionar pensamentos seguindo alguma lógica, durante os } \\
\text { processos de produção e uso do conhecimento científico. }\end{array}$ \\
\hline & Representação & $\begin{array}{l}\text { Capacidade que um cientista possui de expressar uma ideia de forma verbal, } \\
\text { visual, matemática ou outra (por exemplo, ao pensar e/ou produzir analogias e } \\
\text { modelos durante os processos de produção e uso do conhecimento científico). }\end{array}$ \\
\hline & Subjetividade & $\begin{array}{l}\text { Como os modos de pensar e/ou agir de um cientista se relacionam com suas } \\
\text { próprias concepções prévias, que podem ser diferentes das de outro cientista } \\
\text { e não necessariamente embasadas em alguma lógica explícita. }\end{array}$ \\
\hline
\end{tabular}




\begin{tabular}{|c|c|c|}
\hline $\begin{array}{c}\text { Área de } \\
\text { conhecimento }\end{array}$ & Aspecto de NdC & Caracterização do aspecto de NdC \\
\hline \multirow{2}{*}{$\begin{array}{l}\text { Antropologia da } \\
\text { Ciência }\end{array}$} & Incomensurabilidade & $\begin{array}{l}\text { Aspectos envolvendo o conceito de cultura, }{ }^{6} \text { resultando nas ideias de que } \\
\text { não existe cultura boa ou ruim, melhor ou pior; existem diferentes culturas. } \\
\text { Portanto, o conhecimento científico pode ser construído, interpretado e } \\
\text { valorizado de maneiras diferentes, de acordo com as diferentes culturas. }\end{array}$ \\
\hline & Influência cultural & $\begin{array}{l}\text { Influências }{ }^{7} \text { que a cultura pode sofrer e/ou exercer em relação a determinado } \\
\text { conhecimento científico. Assim, indivíduos que manifestam diferentes } \\
\text { culturas podem interpretar um mesmo fenômeno de maneiras diferentes. }\end{array}$ \\
\hline \multirow{6}{*}{$\begin{array}{l}\text { Sociologia da } \\
\text { Ciência }\end{array}$} & Aceitabilidade & $\begin{array}{l}\text { Como o conhecimento é produzido, comunicado, avaliado, revisado e } \\
\text { validado pelos cientistas para que seja aceito como científico. }\end{array}$ \\
\hline & Credibilidade & $\begin{array}{l}\text { Status que os cientistas, as instituições, os prêmios (por exemplo, o Nobel) } \\
\text { e/ou a própria Ciência possuem frente à comunidade científica e/ou à } \\
\text { sociedade. }\end{array}$ \\
\hline & Falibilidade & $\begin{array}{l}\text { Como os cientistas se articulam na comunidade acadêmica perante os erros, } \\
\text { sejam seus ou de outro(s) cientista(s), durante o processo de produção do } \\
\text { conhecimento científico. }\end{array}$ \\
\hline & Incerteza & $\begin{array}{l}\text { Como os cientistas, enquanto grupo de profissionais, tomam consciência, se } \\
\text { posicionam, e/ou, quando possível ou necessário, tomam decisões frente a } \\
\text { incertezas. }\end{array}$ \\
\hline & $\begin{array}{l}\text { Influência } \\
\text { sociopolítica }\end{array}$ & $\begin{array}{l}\text { Influências que a sociedade na qual os cientistas estão inseridos e a política } \\
\text { (local ou global) podem sofrer e/ou exercer durante o processo de produção } \\
\text { do conhecimento científico. Por exemplo, como questões sociais e políticas } \\
\text { iluminadas por diferentes posturas influenciam no desenvolvimento de } \\
\text { pesquisas sobre um determinado tema e/ou como as pesquisas realizadas } \\
\text { interferem no meio social e político. }\end{array}$ \\
\hline & $\begin{array}{l}\text { Interação entre } \\
\text { cientistas }\end{array}$ & $\begin{array}{l}\text { Diferentes modos de interação entre cientistas, por exemplo, parcerias, } \\
\text { contribuições, discordâncias e disputas durante o processo de produção do } \\
\text { conhecimento científico. }\end{array}$ \\
\hline \multirow{8}{*}{$\begin{array}{l}\text { Economia da } \\
\text { Ciência }\end{array}$} & $\begin{array}{l}\text { Acesso ao } \\
\text { conhecimento }\end{array}$ & $\begin{array}{l}\text { Exclusividade do acesso ao conhecimento científico e suas implicações } \\
\text { no valor monetário agregado a ele; ou quem pode usufruir, direta ou } \\
\text { indiretamente, de tal conhecimento. }\end{array}$ \\
\hline & Aplicabilidade & $\begin{array}{l}\text { Interesse das instituições que estão envolvidas nos processos de produção } \\
\text { e/ou aplicação do conhecimento científico na utilização dele. }\end{array}$ \\
\hline & Competitividade & $\begin{array}{l}\text { Competição entre instituiçães ao longo dos processos de produção, } \\
\text { desenvolvimento e/ou aplicação do conhecimento científico, visando a } \\
\text { obtenção de patentes e/ou reconhecimento da inovação. }\end{array}$ \\
\hline & $\begin{array}{l}\text { Fonte de } \\
\text { financiamento }\end{array}$ & $\begin{array}{l}\text { Variedade de instituições, incluindo universidades, centros de pesquisas, } \\
\text { laboratórios industriais, agências governamentais, empresas spin-off, entre } \\
\text { outras, responsáveis pelo financiamento de pesquisas científicas. }\end{array}$ \\
\hline & $\begin{array}{l}\text { Investimento } \\
\text { econômico }\end{array}$ & $\begin{array}{l}\text { Como o investimento ao longo dos processos de produção e aplicação do } \\
\text { conhecimento científico é gradativo e depende dos resultados desses } \\
\text { processos e de fatores sociais, políticos, ambientais, entre outros. }\end{array}$ \\
\hline & Produtividade & $\begin{array}{l}\text { Interesse das instituiçães que estão envolvidas nos processos de produção, } \\
\text { desenvolvimento e aplicação do conhecimento científico na produtividade, } \\
\text { em termos de retorno financeiro dele. }\end{array}$ \\
\hline & Publicidade & $\begin{array}{l}\text { Interesse das instituições que estão envolvidas nos processos de produção } \\
\text { e aplicação do conhecimento científico na divulgação dele com objetivo de } \\
\text { obter financiamento e/ou mercantilização e comercialização. }\end{array}$ \\
\hline & Viabilidade & $\begin{array}{l}\text { Processo de avaliação para definir e/ou justificar os investimentos em } \\
\text { pesquisas científicas. }\end{array}$ \\
\hline
\end{tabular}




\begin{tabular}{|c|c|c|}
\hline $\begin{array}{c}\text { Área de } \\
\text { conhecimento }\end{array}$ & Aspecto de NdC & Caracterização do aspecto de NdC \\
\hline \multirow{5}{*}{$\begin{array}{l}\text { História da } \\
\text { Ciência }\end{array}$} & Influência histórica & $\begin{array}{l}\text { Influências que o contexto histórico pode sofrer e/ou exercer em relação aos } \\
\text { processos de produção e uso de determinado conhecimento científico ao } \\
\text { longo do tempo. }\end{array}$ \\
\hline & Multiplicidade & $\begin{array}{l}\text { Diversas narrativas de, e/ou interpretações diferentes para, um mesmo } \\
\text { episódio histórico em relação a um determinado conhecimento científico. }\end{array}$ \\
\hline & Não linearidade & $\begin{array}{l}\text { Não existência de um único caminho para o desenvolvimento do conhecimento } \\
\text { científico, incluindo os resgastes de ideias apresentadas em pesquisas } \\
\text { anteriores, os imprevistos e as mudanças nas pesquisas sobre um determinado } \\
\text { conhecimento científico que foram ocorrendo ao longo do tempo. }\end{array}$ \\
\hline & Progressividade & $\begin{array}{l}\text { Processo pelo qual um determinado conhecimento científico foi produzido, } \\
\text { comunicado, avaliado, revisado e validado de maneira gradativa ao longo } \\
\text { do tempo. Assim, fica evidenciado que o conhecimento não é construído de } \\
\text { uma única vez e que os processos de produção do conhecimento científico } \\
\text { demandam tempo para ocorrer. }\end{array}$ \\
\hline & Provisoriedade & $\begin{array}{l}\text { Ocorrência de mudanças em um determinado conhecimento científico ao } \\
\text { longo do tempo, havendo o abandono de algumas ideias em detrimento de } \\
\text { novas construções, o que é consequência de o processo ser dinâmico, não } \\
\text { linear e progressivo. }\end{array}$ \\
\hline
\end{tabular}

Os aspectos de $\mathrm{NdC}$ relacionados a cada uma das áreas de conhecimento podem ser usados como categorias bem definidas na análise de dados coletados em contextos de ensino cujo objetivo seja investigar a visão sobre Ciências de sujeitos envolvidos em tais contextos. Por este motivo, e considerando a amplitude deles, optamos por usar o MoCEC v.2 como ferramenta de análise de dados.

\section{PROCEDIMENTOS DE ANÁLISE DOS DADOS}

Utilizando as caracterizações dos aspectos de NdC definidas no MoCEC v.2, identificamos, no portfólio de Ana, indícios de expressão dos aspectos de $\mathrm{NdC}$ relacionados a cada uma das áreas de conhecimento. Durante a identificação, quando a PQFI apresentou, em momentos diferentes da atividade, as mesmas relaçôes, o aspecto expresso foi classificado apenas uma vez, porque entendemos que houve uma repetição da ideia. Ressaltamos que foi realizada a triangulação entre árbitros (Cohen, Manion, \& Morrison, 2011), ou seja, a análise foi realizada de forma independente pelos autores, sendo os resultados posteriormente comparados e discutidos até que se atingisse consenso.

A partir da análise, apontamos quais aspectos a PQFI expressou de forma mais frequente ao longo da disciplina ou em uma mesma atividade, e identificamos as relações entre o contexto da atividade e a expressão de determinados aspectos.

\section{RESULTADOS E DISCUSSÕES}

Todos os aspectos de NdC identificados no portfólio de Ana são apontados na Figura 3. Nas duas primeiras colunas são apresentadas, respectivamente, as áreas de conhecimento e os aspectos de $\mathrm{NdC}$ relacionados à cada área. Nas demais colunas, mostramos o número de expressão de cada aspecto relacionado às oito atividades (A1 a A8). Na última coluna indicamos o somatório $(\boldsymbol{\Sigma})$ de expressóes de cada aspecto no portfólio. Por fim, destacamos que as lacunas em branco indicam a não expressão do aspecto no registro referente às atividades. 
Considerando a extensão do artigo, discutimos em detalhes apenas os resultados relativos aos aspectos expressos por Ana com maior frequência (destacados em negrito), isto é: (i) aqueles que foram identificados nos registros referentes a quatro ou mais atividades; e (ii) aqueles que foram identificados mais de uma vez no registro de uma mesma atividade, pois consideramos que estes foram mais significativos para ela. Em relação às áreas de Antropologia e Economia da Ciência, apesar de os aspectos não terem sido expressos com frequência, discutimos o mais recorrente nos registros, a fim de contribuir para a percepção do leitor sobre como aspectos destas áreas podem ser expressos.

Figura 3. Aspectos relacionados às áreas de conhecimento identificados nos registros presentes no portfólio de Ana.

\begin{tabular}{|c|c|c|c|c|c|c|c|c|c|c|}
\hline $\begin{array}{c}\text { Área de } \\
\text { conhecimento }\end{array}$ & Aspecto de NdC & A1 & $\mathbf{A 2}$ & A3 & A4 & A5 & A6 & A7 & A8 & $\Sigma$ \\
\hline \multirow{2}{*}{$\begin{array}{l}\text { Filosofia da Ciência } \\
\text { (FC) }\end{array}$} & Epistemologia & 1 & 1 & 1 & 2 & 2 & 2 & 3 & 2 & 14 \\
\hline & Lógica & 1 & 1 & & & & & & & 2 \\
\hline \multirow{9}{*}{$\begin{array}{l}\text { Psicologia da Ciência } \\
\text { (PC) }\end{array}$} & Criatividade & & & & 1 & & & & & 1 \\
\hline & Influência motivacional & & & & & & 1 & 2 & & 3 \\
\hline & Inteligência & & & & 1 & 1 & & & & 2 \\
\hline & Limitação & & & & & & 2 & & & 2 \\
\hline & Não linearidade do pensamento & & & & 1 & 1 & & & & 2 \\
\hline & Objetividade & & & & & & 1 & & & 1 \\
\hline & Personalidade & & & & 1 & 1 & 1 & 1 & & 4 \\
\hline & Racionalidade & 1 & & & & & & & & 1 \\
\hline & Subjetividade & 1 & 2 & & & & & & & 3 \\
\hline $\begin{array}{l}\text { Antropologia da } \\
\text { Ciência }(A C)\end{array}$ & Influência cultural & 1 & & & 1 & & & & & 2 \\
\hline \multirow{4}{*}{$\begin{array}{c}\text { Sociologia da Ciência } \\
\text { (SC) }\end{array}$} & Aceitabilidade & & & & 1 & & & & & 1 \\
\hline & Credibilidade & & & & 2 & 1 & 2 & & & 5 \\
\hline & Influência sociopolítica & 2 & 1 & & 3 & 1 & 3 & 2 & 1 & 13 \\
\hline & Interação entre cientistas & & 1 & 1 & 1 & 1 & & 1 & & 5 \\
\hline \multirow{2}{*}{$\begin{array}{l}\text { Economia da Ciência } \\
\text { (EC) }\end{array}$} & Acesso ao conhecimento & & & & & & 1 & & 1 & 2 \\
\hline & Aplicabilidade & & & & & & & & 1 & 1 \\
\hline
\end{tabular}




\begin{tabular}{|c|c|c|c|c|c|c|c|c|c|c|}
\hline $\begin{array}{c}\text { Área de } \\
\text { conhecimento }\end{array}$ & Aspecto de NdC & A1 & A2 & A3 & A4 & A5 & A6 & A7 & A8 & $\Sigma$ \\
\hline \multirow{5}{*}{$\begin{array}{l}\text { História da Ciência } \\
\text { (HC) }\end{array}$} & Influência histórica & 1 & 1 & & & 1 & 1 & & 1 & 5 \\
\hline & Multiplicidade & & & & 1 & & & & & 1 \\
\hline & Não linearidade & & & & 1 & & & & & 1 \\
\hline & Progressividade & & & 1 & & & 1 & & & 2 \\
\hline & Provisoriedade & & 1 & & 1 & & & & & 2 \\
\hline
\end{tabular}

Com relação à Filosofia da Ciência, Ana expressou o aspecto epistemologia nos registros sobre todas as atividades presentes no portfólio (Figura 3) e, ao longo da disciplina, este foi o aspecto mais frequentemente identificado nas manifestações de suas ideias. Observamos a maior ocorrência desse aspecto em A7, a partir das reflexôes de Ana sobre o processo de construção do conhecimento científico como um todo e a importância de, como futura professora, entender sobre tal processo, como destacado no trecho apresentado:

Acho muito importante que nós, futuros professores, possamos entender como se dá o processo de evol ução e construção da ciência, porque se nós não conhecemos, nós passamos uma ideia errada de ciência e não conseguimos realmente explanar a humanidade que tem essa ciência que é construída por homens e que por diversas vezes são colocados como seres incomuns. (ANA, A7, grifo nosso)

Neste exemplo, além de refletir sobre a natureza do conhecimento científico, Ana enfatiza a importância disso para os professores, ressaltando que a falta de conhecimento sobre $\mathrm{NdC}$ pode implicar na permanência de um ensino inadequado sobre Ciências. Esse apontamento vai ao encontro do que tem sido destacado na literatura, sobre a importância da formação de professores para um ensino de Ciências mais próximo da realidade (por exemplo, Justi \& Mendonça, 2016; Martins, 2006; Oki \& Moradillo, 2008). Assim, ela parece valorizar esses conhecimentos para o ensino de Ciências, contrariando a visão de que eles são menos importantes do que os conceitos científicos, concepção compartilhada por muitos professores (Maurines \& Beaufils, 2012).

A partir das notas de campo, identificamos que, em uma das aulas finais da disciplina, quando foi discutido um estudo de caso histórico sobre a cientista Marie Curie, Ana afirmou que: "coisas do primeiro semestre estão fazendo sentido agora, porque estou entendendo como a Ciência é feita”. Essa fala é uma evidência de que, ao final da disciplina, Ana tinha uma visão mais ampla sobre Ciências e que, devido a isso, ela trouxe em seus registros mais reflexões sobre as limitações e alcances do conhecimento científico - o que pode explicar a maior frequência do aspecto epistemologia. Além disso, Ana pareceu reconhecer as deficiências de sua formação, em termos do distanciamento da aprendizagem sobre os conceitos científicos e o contexto de produção desses conceitos, reafirmando as limitaçốes na formação de professores apontadas na literatura (por exemplo, Justi \& Mendonça, 2016; Martins, 2006; Oki \& Moradillo, 2008).

Com relação aos aspectos de $\mathrm{NdC}$ relacionados a área de Psicologia da Ciência, grande parte deles, nove dentre os treze, foram identificados, e em quase todas as atividades, com exceção de A3 e A8 (Figura 3). Nos registros referentes a A6 e A7, caracterizamos o aspecto influência motivacional quando, por exemplo, Ana reconheceu as motivações da cientista Marie Curie ao relatar que ela continuava seu trabalho apesar de todas as dificuldades: "Marie Curie foi corajosa e muito inteligente. Apesar de toda dificuldade não se deixa abalar e alcança seus objetivos” (A6). Em A7, Ana retomou as motivações intrínsecas de Marie Curie e apontou as motivações extrínsecas provenientes dos estímulos vindos de seu marido Pierre Curie, destacando que o apoio dele foi fundamental para as conquistas dela, visto que ele sempre fazia questão de reconhecer o trabalho de sua esposa. Assim, Ana reconheceu a motivação pessoal de cientistas na produção do conhecimento científico e para a continuidade dos trabalhos. Além disso, ela destacou a contribuição da motivação externa 
para que os cientistas permaneçam no caminho da pesquisa, dando indícios de que não concebe cientistas como "gênios" ou "sujeitos que trabalham isoladamente", uma visão sobre Ciências que é recorrente entre professores e alunos (Bomfim, Reis, \& Guerra, 2016; Gil Pérez et al., 2001; Guerra-Ramos, 2012).

O aspecto limitação aparece duas vezes em A6. Primeiro, Ana discute sobre as condições precárias do ambiente de trabalho de Marie Curie, reconhecendo que isso dificultava as produçóes da cientista, apesar de não a impedir de fazer suas pesquisas:

As condiçôes de trabalho em que ela desenvolvia seus experimentos eram precárias. O laboratório dela foi 'adaptado'. Era uma sala com janelas de vidro, que foi concedida pelo diretor da escola de física na qual Pierre trabalhava. Um tempo depois, eles passam a trabalhar num hangar cedido. Lá não tinha nada que regulasse a temperatura, no verão era muito quente e no inverno as temperaturas caiam drasticamente, mal tinha proteção contra chuvas. Mesmo nessas condiçóes ela continuava seu trabalho árduo. (ANA, A6).

Depois, ela refletiu sobre as dificuldades relativas ao fato de ela ser uma mulher em um meio dominado por homens, apontando que para a cientista ter algum trabalho reconhecido ela precisava se esforçar mais do que os demais cientistas da época.

Como evidenciado na Figura 3, o aspecto personalidade foi expresso por Ana em quatro atividades (A4 a A7). Em A4 e A5, observamos a sobreposição dos aspectos inteligência e não linearidade do pensamento. Ana expressou o aspecto personalidade quando discutiu como as características de Thompson e Marie Curie contribuíram para que eles fizessem escolhas determinantes para o processo de produção de conhecimento. Por exemplo, em A4, ela destacou que a forma como Thompson se relacionava com o conhecimento foi determinante para que ele desenvolvesse seus estudos sobre a teoria atômica:

Thompson, ao longo da sua pesquisa sobre modelos atômicos, não fica estagnado, procura sempre ler e incorporar ao seu trabalho as novas tendências teóricas da época e aceita o novo de forma mais pacifica. Isso ajuda consideravelmente a evolução da ciência. (ANA, A4).

Para Ana, as características da personalidade do cientista como ser receptivo à novas ideias e ser ávido por conhecimento, resultaram em escolhas inteligentes durante a produção de conhecimento sobre a estrutura da matéria. Nesse mesmo trecho, ela também expressou o aspecto não linearidade do pensamento quando refletiu sobre como a personalidade de Thompson contribuiu para que ele incorporasse em seus estudos novas ideias e repensasse suas proposiçóes.

Ainda na área de Psicologia da Ciência, observamos a expressão do aspecto subjetividade nos registros referentes às primeiras atividades (A1 e A2), quando Ana assumia que as concepções teóricas dos cientistas influenciavam na produção de conhecimento científico. Isto foi identificado, por exemplo, quando ela comentou sobre os trabalhos de Paracelso:

[...] Paracelso consegue fazer uma ligação entre a religião e a 'ciência' quando ele diz que a criação do universo pode ser vista como um processo alquímico de separação e a partir disso os processos seguintes deveriam ser compreendidos de forma 'química'. [...] A relação com a crença ainda tem uma ligação muito forte nas explicações dos fenômenos estudados mesmo que testes em laboratório sejam realizados, não se é possível ainda compreender de forma 'racional' e independente os fenômenos da natureza. (ANA, A2).

Neste trecho, Ana reconheceu que a ligação de Paracelso com a religião interferiu em sua forma de construir conhecimento científico e apontou que esse tipo de relação ainda está presente nas concepções de cientistas da atualidade. Dessa forma, a partir desse episódio de HQ e de estudos da iatroquímica, ela apresentou reflexões sobre o processo de produção de conhecimentos científicos na atualidade, apontando que tal processo não segue uma lógica empírico-indutivista (Gil Pérez et al., 2001). 
Considerando a área de Antropologia da Ciência, o aspecto influência cultural foi observado em dois momentos, A1 e A4. No material básico e na aula referente à $\mathrm{A} 1$, foram discutidas diversas formas de se pensar sobre a matéria na pré-história e na antiguidade. A partir disso, Ana destacou que:

Todas as teorias estão relacionadas ao contexto histórico vivido por cada 'filósofo' e isso mostra que a construção de conhecimento e a explicação dos fenômenos estão diretamente ligados $\grave{a}$ cultura e à sociedade em que o pensador está inserido. (ANA, A1, grifo nosso).

Percebemos que Ana reconheceu que a forma de se pensar sobre a matéria está relacionada à cultura da época na qual esse conhecimento foi construído. Neste trecho também foram identificados os aspectos influência sociopolítica (SC) e influência histórica (HC).

Em termos de Sociologia da Ciência, os aspectos credibilidade, influência sociopolítica e interação entre cientistas foram os mais frequentes nas manifestaçốes de Ana.

Identificamos a expressão do aspecto credibilidade nos registros referentes às A4 a A6 (Figura 3). Por exemplo, nos registros referentes à $\mathrm{A} 5 \mathrm{e} \mathrm{A} 6$, Ana trouxe discussóes sobre o reconhecimento do trabalho de Becquerel relacionado a "descoberta" da radioatividade. Em ambos, ela apontou que os trabalhos de Becquerel não foram suficientes para concluir que ele "descobriu" a radioatividade, pois apesar de ter sido o primeiro a observar o fenômeno, ele falhou em interpretá-lo. Ela ainda salientou que Marie Curie contribuiu mais significativamente para o entendimento desse fenômeno, mas teve mais dificuldades para ter suas contribuiçốes reconhecidas em função de ser uma cientista mulher em uma época em que mulheres tinham pouquíssimo ou nenhum espaço na sociedade. Ao final dos registos referentes à $\mathrm{A} 6$, Ana atribui à facilidade de Becquerel em ter seus trabalhos aceitos ao fato de ele ter uma família influente no meio científico:

O caso da descoberta da radioatividade se aproxima bastante do caso da descoberta do oxigênio. Becquerel e Lavoisier, por possuírem influência tanto na comunidade científica quanto na sociedade por questôes políticas, ganham um prêmio importantíssimo dentro da ciência. A diferença é que Lavoisier mereceu o prêmio por todas as contribuiçôes feitas por ele. Já Becquerel, sem explicar o fenômeno observado e simplesmente por 'parafrasear' trabalhos já publicados anteriormente consegue um prêmio desses. Fica evidente que isso só aconteceu porque sua família era toda de cientistas e seu pai e seu avô foram grandes cientistas, tendo então bastante influência na comunidade científica. Marie que foi muito mais decisiva nas contribuiçóes sobre radioatividade, precisa se justificar e lutar para merecer o prêmio [Nobel]. [...] O estudo desse episódio histórico me levou a refletir sobre todas as lutas que foram travadas pela Marie Curie, para que hoje nós tivéssemos um maior espaço na comunidade científica. É nítido que ainda hoje a ciência é predominantemente masculina. Porém o espaço é muito mais amplo e 'igualitário'. ${ }^{8}$ (ANA, A6).

Nesse caso, Ana destacou as dificuldades que Marie Curie teve para desenvolver seus trabalhos e conquistar seu espaço no meio acadêmico. Julgamos que as consideraçôes dela se enquadram no aspecto credibilidade porque ela discute o impacto da falta de status da cientista frente à comunidade acadêmica da época com mais ênfase, mesmo tendo relacionado isso ao contexto cultural e social da época, além de ter discutido o impacto do status da família de Becquerel no meio acadêmico. Assim, neste trecho, aparecem sobrepostos os aspectos de limitação (PS) e influência sociopolítica. Além disso, Ana traça um paralelo com o mundo contemporâneo, admitindo as influências de uma sociedade machista e patriarcal ainda nos dias de hoje. Porém, ela reconhece o progresso realizado em relação a essa pauta e salienta a importância da cientista Marie Curie para o reconhecimento e ampliação de possibilidades de atuação das mulheres nas Ciências.

Em relação ao aspecto influência sociopolítica, ele foi identificado treze vezes nos registros presentes nos portfólios referentes a quase todas as atividades, com exceção de A3 (Figura 3). Por exemplo, em A6, Ana discutiu as interferências sociais no contexto da descoberta da radioatividade sobre os responsáveis pelo uso desse conhecimento para se fabricar armas, devido ao contexto de guerra da época: 
[A Ciência] não é neutra, apolítica. Sofre interferências sociais e suas evoluçôes acompanham o contexto vivido. Por exemplo, na época dos estudos de radioatividade, as questões políticas estavam cada vez mais tensas, tendo ocasionado duas Guerras Mundiais. Nesse período se viu a necessidade de esconder os elementos radioativos porque já se sabia que eles tinham potencial para construir armas químicas e logo depois o conhecimento científico foi usado infelizmente para a construção de uma bomba atômica. (ANA, A6, grifo nosso).

Neste e em outros registros referentes à $\mathrm{A} 6$, observamos que ela refletiu sobre a influência da sociedade na produção de conhecimentos, tanto a partir do acesso dos cientistas aos meios de divulgação de conhecimentos e à comunidade científica quanto a partir da influência da produção de conhecimentos na sociedade, visto que ela ressaltou como conhecimentos sobre as partículas subatômicas influenciaram e mudaram o contexto de guerra no mundo. Então, Ana destacou as relaçốes entre a Ciência e sociedade, demonstrando que não concebia a Ciência de forma neutra e isolada, ou ainda, que não tinha uma visão salvacionista da Ciência.

O último aspecto relacionado à área de Sociologia da Ciência, interação entre cientistas, foi observado nos registros referentes a mais da metade das atividades, sendo uma ocorrência por atividade. Por exemplo, Ana evidenciou entender tal aspecto ao discutir sobre a descoberta do elemento químico Oxigênio, quando reconheceu as contribuiçốes de Lavoisier, mas enfatizou que: "Lavoisier esteve sempre rodeado de cientistas que ajudaram e fizeram junto com ele parte da construção da Química” (A3). A partir desta afirmativa, ela apontou que não era adequado atribuir o título de "pai da Química" a Lavoisier, visto que os trabalhos dele estavam relacionados a outros estudos realizados na época, cujos autores também deveriam ser reconhecidos. Mais uma vez, Ana pareceu refletir sobre o fato de que cientistas não trabalham sozinhos e que os conhecimentos produzidos, mesmo quando inéditos, estão relacionados a outros estudos conduzidos e discutidos naquele período.

Com relação à área de Economia da Ciência, identificamos apenas dois aspectos, nos registros referentes às últimas atividades (A6 e A8). Por exemplo, nesta última, ao relatar sobre uma proposta de ensino para a inserção de HQe de aspectos de NdC na Educação Básica, Ana expressou ideias referentes ao aspecto acesso ao conhecimento quando discutiu a relação entre o desenvolvimento de pesquisas sobre radiação e o contexto de guerra:

Outro fator importante foi a questão decisiva na utilização desse conhecimento adquirido na Guerra.

Quem detinha conhecimento estava um passo à frente na guerra, as descobertas eram cada vez mais presentes e o progresso era cada vez maior. (ANA, A8, grifo nosso).

Esse trecho foi assim classificado porque, a partir de elementos relacionados à História da Ciência sobre a existência de partículas subatômicas e elementos radioativos, Ana refletiu sobre o valor que o conhecimento científico pode alcançar, de forma que relações de poder entre sujeitos e naçóes podem estar relacionadas a quem pode pagar pelo conhecimento ou ter acesso a ele.

Finalmente, em termos de História da Ciência, todos os aspectos foram identificados nos registros de Ana. Isto pode ser justificado devido ao fato de nossos dados terem sido coletados em um contexto de ensino-aprendizagem de HQ. Além disso, destacamos que o aspecto influência histórica foi identificado em grande parte dos registros referentes às atividades, muitas vezes juntamente com o aspecto influência sociopolítica (SC).

De forma geral, identificamos influência histórica quando Ana trouxe reflexões sobre as influências do contexto da época na produção de conhecimentos científicos, reconhecendo que eles estão intrinsicamente relacionados a seus contextos históricos de produção. Por exemplo, nos registros referentes à A2, Ana discutiu o impacto da religião nas explicaçóes dadas, naquela época, para fenômenos da natureza; nos registros referentes às $\mathrm{A} 5$ e A6, ela atribuiu ao patriarcado parte dos desafios enfrentados por Marie Curie; e nos registros referentes à $\mathrm{A} 8$, ao relatar os objetivos de sua proposta de ensino voltada para a Educação Básica, ela salientou a interferência do contexto de guerra na produção de conhecimentos científicos, destacando as grandes produçôes científicas nesses períodos. 
Por fim, a partir da discussão detalhada dos resultados, esperamos que o leitor tenha percebido como as caracterizaçôes dos aspectos de $\mathrm{NdC}$ relacionados às áreas de conhecimento (Figura 2) podem ser utilizadas como categorias bem definidas na análise de dados coletados em um contexto de ensino-aprendizagem de HQ, favorecendo a visualização da interpretação desses aspectos nos dados analisados.

\section{CONCLUSÕES E IMPLICAÇÕES}

A partir da análise, principalmente, dos registros contidos no portfólio de uma PQFI redigido ao longo de uma disciplina de $\mathrm{HQ}$, identificamos a ocorrência de 23 dentre os 37 aspectos de $\mathrm{NdC}$ relacionados a todas as áreas de conhecimento representadas no MoCEC v.2, isto é, mais de 60\% dos aspectos propostos e caracterizados no modelo. Tal variedade de aspectos de $\mathrm{NdC}$ indica que Ana manifestou uma visão ampla sobre Ciências.

Ao analisar como os aspectos de $\mathrm{NdC}$ foram expressos nos registros referentes às atividades vivenciadas ao longo da disciplina de $\mathrm{HQ}$, percebemos que o uso de diferentes elementos relacionados à $\mathrm{HQ}$, as discussões explícitas sobre as características da Ciência evidenciadas em cada um deles, e os convites à reflexão relativos à aprendizagem sobre Ciências, ocorridos em todas as oito atividades, contribuíram principalmente para que Ana:

I. refletisse sobre conceber a Ciência como uma prática social, apontando que cientistas constituem grupos com regras, condutas e hábitos próprios e que, durante a produção de conhecimentos científicos, há embates e colaboraçóes entre os membros desses grupos;

II. percebesse as influências de contextos históricos na produção de conhecimentos científicos; e

III.entendesse o significado de Ciência hoje e como ela se desenvolveu/desenvolve.

No que diz respeito a como Ana expressou os aspectos de $\mathrm{NdC}$ relacionados à área de Psicologia da Ciência, apontamos que a ocorrência deles foi favorecida por discussões de elementos relacionados à HQ nos quais a figura de um cientista foi enfatizada como ocorreu, por exemplo, durante as discussóes sobre os trabalhos de Thomson, Becquerel e Marie Curie. Em relação a isso, destacamos que há necessidade de o professor formador ter o cuidado de não retratar o cientista como "gênio" ou focar as discussões em um único trabalho daquele cientista, pois isso pode afastar os alunos das carreiras científicas e diminuir o interesse deles pelas Ciências (Allchin, 2013; Gil Pérez et al., 2001), por não identificarem algumas de suas características ou elementos de suas personalidades nas dos cientistas apresentados (Bomfim et al., 2016). Assim, para uma discussão mais adequada sobre aspectos de $\mathrm{NdC}$ presentes nessa área, precisamos ir além das tradicionais caixas (boxes) com informaçóes sobre cientistas apresentadas em livros didáticos (Porto, 2019). Entendemos ser fundamental que as características emerjam de um contexto no qual a produção de conhecimentos científicos seja retratada com todos os seus desafios, parcerias etc. (Allchin et al., 2014).

O fato de os aspectos de $\mathrm{NdC}$ relacionados às áreas Economia e Antropologia da Ciência terem sido identificados poucas vezes pode indicar que o trabalho apenas com casos históricos é insuficiente para gerar um contexto amplo de ensino-aprendizagem sobre Ciências. Assim, endossamos os apontamentos de Allchin et al. (2014) sobre a necessidade de o ensino sobre Ciências envolver discussóes também a partir de atividades investigativas e casos contemporâneos. Em outras palavras, entendemos que é importante usar abordagens complementares para que o ensino englobe uma variedade maior de aspectos $\mathrm{de} \mathrm{NdC}$ e, consequentemente, de áreas de conhecimento. Por exemplo, consideramos que discussóes sobre a comercialização do conhecimento científico (relacionados à área de Economia da Ciência) podem ser mais evidentes em discussóes de casos contemporâneos do que de casos históricos, nos quais a comercialização de conhecimento científico tende a não ser enfatizada (talvez até por ser mais evidente em tempos mais recentes).

Sobre os aspectos relacionados à área de Antropologia da Ciência, apontamos que talvez a expressão deles não esteja diretamente ligada à abordagem de ensino adotada e sim à temática selecionada. Assim, ao se 
discutir, por exemplo, outros tipos de conhecimento para além dos científicos, como os saberes tradicionais, eles possam vir a ser expressos.

Ressaltamos que o trabalho com elementos relacionados à HQ pode contribuir para o ensino sobre Ciências, assim como ressaltado em outros trabalhos da área (Martins, 2006; Oki \& Moradillo, 2008). Porém, salientamos que o ensino de $\mathrm{NdC}$ e HQ no Ensino Superior não deve ocorrer apenas em uma disciplina e a partir de uma única abordagem de ensino. É importante que os futuros professores vivenciem essas discussões ao longo de toda sua formação, isto é, tanto em disciplinas de cunho pedagógico quanto naquelas focadas em conteúdos químicos, visto que os estudos sobre como esses conhecimentos foram desenvolvidos são parte desses conteúdos e podem contribuir para ampliar a aprendizagem deles (Matthews, 2012).

Maurines e Beaufils (2012) destacam que muitos professores em exercício consideram que o ensino de conceitos científicos é mais importante do que o ensino sobre Ciências, e mesmo aqueles professores que consideram o ensino de HQ importante, enfrentam dificuldades para realizá-lo em salas de aula. Por isso, apontamos como fundamental o envolvimento de futuros professores em discussóes sobre Ciências e sobre HQ também em disciplinas como Química Orgânica, Analítica, entre outras, para que eles possam aprender juntamente sobre os conceitos, seus contextos de produção, sujeitos envolvidos etc.

Além disso, Carlson e Daehler (2019) destacam que os conhecimentos pedagógicos de conteúdo pessoal do professor refletem as suas experiências de ensino, o que evidencia a necessidade de os professores em formação inicial vivenciarem um ensino mais coerente com o que é esperado que eles façam em salas de aula. Em outras palavras, em geral, durante a formação inicial, os professores vivenciam o ensino de conceito de forma conteudista e deslocado de seus contextos de produção (Schnetzler, 2019), o que pode contribuir para os resultados apontados por Maurines e Beaufils (2012). Entretanto, reconhecemos que isto implica no fato de os professores formadores terem desenvolvido seus conhecimentos sobre Ciências e terem conhecimentos relacionados ao como ensinar sobre Ciências, o que configura um outro desafio a ser superado na formação de professores (Schnetzler, 2019).

Ainda no que tange à formação de professores, apontamos que uma limitação desse estudo é não investigar os aspectos relacionados à Ciência manifestados pela PQFI ao conduzir situaçốes de ensino envolvendo elementos relacionados à $\mathrm{HQ}$ e aspectos de $\mathrm{NdC}$. Apesar de uma das atividades da disciplina estar relacionada à elaboração de uma proposta de ensino sobre a inserção de HQ e de aspectos de NdC na Educação Básica, apenas discussóes dessa natureza podem não ser suficientes para que o professor seja capaz de trabalhar nesta perspectiva.

Nesse sentido, endossamos as discussóes presentes na literatura sobre a importância das disciplinas do tipo prática como componente curricular (Diniz-Pereira, 2016; Pereira \& Mohr, 2017), as quais visam aproximar os futuros professores da realidade das salas de aulas. Reconhecemos a necessidade de, nos cursos de formação de professores, serem oferecidas não apenas oportunidades de futuros professores planejarem propostas de ensino como também de conduzi-las. Assim, eles poderão desenvolver e mobilizar conhecimentos pedagógicos de conteúdo coletivo (Carlson \& Daehler, 2019) - que estão relacionados tanto aos conhecimentos de HQ quanto sobre como ensinar Química envolvendo HQ -, uma vez que terão experiências de ensino orientadas pelos professores supervisores.

Nesses contextos, poderiam ser investigadas outras questóes de pesquisa como, quais aspectos de $\mathrm{Na}$ tureza da Ciência são considerados por professores de Química em formação inicial ao planejarem e conduzirem situaçốes de ensino envolvendo História da Química? Investigações desta natureza poderiam culminar na proposição de diretrizes para cursos de formação de professores de Ciências na perspectiva aqui discutida.

Considerando nossa experiência em usar o MoCEC v.2 como ferramenta de análise, reconhecemos sua adequação e apontamos que ele pode ser utilizado em estudos futuros que busquem investigar visóes sobre Ciências de professores, sem a intenção de encaixá-las em modelos predefinidos, algo que tende a ocorrer 
quando essa análise é baseada em questionários (Guerra-Ramos, 2012; Moura et al., 2020). Ao contrário, salientamos que o MoCEC v.2 é uma ferramenta adequada para caracterizar as ideias sobre Ciências de sujeitos quando essa investigação ocorre em contextos de ensino.

Por outro lado, a extensão da ferramenta de análise e a consequente necessidade de entender o significado de vários aspectos de $\mathrm{NdC}$ podem dificultar o seu uso por pesquisadores menos experientes. Assim, concordamos com Santos et al. (2020) em relação ao uso da ferramenta exigir que o pesquisador compreenda os limites e alcances de cada área de conhecimento, bem como o significado dos aspectos de $\mathrm{NdC}$ relacionados a cada uma delas.

Por fim, ressaltamos que os resultados apresentados e discutidos neste artigo, assim como as reflexões sobre o uso do MoCEC v.2, podem contribuir para o desenvolvimento de outras pesquisas na área ao sinalizar as potencialidades e limitações da ferramenta de análise empregada. Além disso, a partir de tais resultados e reflexões foi possível elucidar a importância de uma formação de professores voltada para um ensino de e sobre Ciências mais autêntico, ampliando assim as perspectivas de pesquisas com relação à introdução de NdC no Ensino Superior, bem como fomentando o diálogo na área de Educação em Ciências sobre a respectiva temática.

\section{AGRADECIMENTOS}

Os autores agradecem: à CAPES e FAPDF, pelos auxílios financeiros, e à Rosária Justi, pela leitura crítica do artigo e apontamentos que contribuíram para esta produção.

\section{REFERÊNCIAS}

Alfonso-Goldfarb, A. M. (1987a). Algumas reflexões sobre a Genealogia e a Gênese da Alquimia. In Da Alquimia à Química (pp. 41-68). São Paulo: nova Stella: Editora da Universidade de São Paulo.

Alfonso-Goldfarb, A. M. (1987b). Robert Boyle e a Introdução do Universo Mecanicista na Química. In Da Alquimia à Quimica (pp. 173-207). São Paulo: nova Stella: Editora da Universidade de São Paulo.

Alfonso-Goldfarb, A. M., Ferraz, M. H. M., Beltran, M. H. R., \& Porto, A. P. (2016). Séculos XVII e XVIII: a química em busca de novos caminhos. In Percursos da História da Química (pp. 35-59). São Paulo: Editora Livraria da Física.

Allchin, D. (2011). Evaluating Knowledge of the Nature of (Whole) Science. Science Education, 95(3), 518-542. doi:10.1002/sce.20432

Allchin, D. (2013). Teaching the nature of science: Perspectives and resources. St. Paul: SHiPS Education Press.

Allchin, D., Andersen, H. N., \& Nielsen, K. (2014). Complementary Approaches to Teaching Nature of Science: Integrating Student Inquiry, Historical Cases, and Contemporary Cases in Classroom Practice. Science Education, 98(3), 461-486. doi:10.1002/sce.21111

Anunciação, B. C. P., Neto, H. S. M., \& Moradillo, E. F. (2014). Robert Boyle no Contexto da Transição para a Ciência Moderna: Elementos para uma Análise Sócio-Histórica Revista Ideação, 29(1), 165-192. doi:g10.13102/ideac.v1i29.1345

Bomfim, J., Reis, J. C., \& Guerra, A. (2016). Problematizando a ideia de gênios isolados: Mayer e Joule no episódio da conservação da energia. Revista Tecné, Episteme e Didaxis: TED, Extraordinário, 1264-1270. Retrieved from https:// revistas.pedagogica.edu.co/index.php/TED/article/view/4736

Bortolotto, A., Lobato, C. B., Tonetto, S. R., Ferraz, M. H. M., Alfonso-Goldfarb, A. M., \& Beltran, M. H. R. (2012). Dissecando a Matéria entre os Séculos XVIII-XX. In História da Ciência: Tópicos Atuais 2 (pp. 103-130). São Paulo: Editora Livraria da Física.

Carlson, J., \& Daehler, K. R. (2019). The Refined Consensus Model of Pedagogical Content Knowledge in Science 
Education. In A. Hume, R. Cooper, \& A. Borowski (Eds.), Repositioning Pedagogical Content Knowledge in Teachers' Knowledge for Teaching Science (pp. 77-92). Singapore: Springer.

Carvalho, A. D. (2010). A constituição Particulada da Matéria. (Trabalho de conclusão de curso). Universidade Federal do Rio de Janeiro, Rio Janeiro.

Carvalho, A. M. P. (2013). O ensino de Ciências e a proposição de sequências de ensino investigativas. In A. M. P. Carvalho (Ed.), Ensino de Ciências por Investigação (pp. 1-20). São Paulo: Cengage Learning.

Chagas, A. P. (2011). Existem átomos? (abordando Jean Perrin). História da Ciência e Ensino: Construindo interfaces, 3,7-16. Retrieved from https://revistas.pucsp.br/hcensino/article/view/5605

Cohen, L., Manion, L., \& Morrison, K. (2011). Research Methods in Education (7th ed.). New York: Routledge.

Diniz-Pereira, J. E. (2016). [DCN’s para a formação inicial e continuada em nível superior: concepçôes e desafios.].

Erduran, S., \& Dagher, Z. R. (2014). Reconceptualizing the Nature of Science for Science Education: Scientific Knowledge, Practices and Other Family Categories. Dordrecht: Springer.

Filgueiras, C. A. L. (1995). A Revolução Química de Lavosier: Uma Verdadeira Revolução? Química Nova, 18(2), 219-224.

Gil Pérez, D., Montoro, I. F., Alis, J. C., Cachapuz, A., \& Praia, J. (2001). Para uma imagem não deformada do trabalho científico. Ciência E̊ Educaşão, 7(2), 125-153. doi:10.1590/S1516-73132001000200001

Guerra-Ramos, M. T. (2012). Teachers' Ideas About the Nature of Science: A Critical Analysis of Research Approaches and Their Contribuition to Pedagogical Practice. Science E'Education, 21(5), 631-655. doi:10.1007/s11191-011-9395-7

Hanuscin, D. L. (2013). Critical Incidents in the Development of Pedagogical Content Knowledge for Teaching the Nature of Science: A Prospective Elementary Teacher's Journey. Journal of Science Teacher Education, 24(6), 933-956. doi:10.1007/s10972-013-9341-4

Hanuscin, D. L., Akerson, V. L., \& Phillipson-Mower, T. (2016). Integrating Nature of Science Instruction into a Physical Science Content Course for Preservice Elementary Teachers: NOS Views of Teaching Assistants. Science Education, 90(5), 912-935. doi:10.1002/sce.20149

Irzik, G., \& Nola, R. (2011). A Family Resemblance Approach to the Nature of Science for Science Education. Science E Education, 20(7-8), 591-607. doi:10.1007/s11191-010-9293-4

Justi, R., \& Erduran, S. (2015). Characterizing Nature of Science: A supporting model for teachers. Paper presented at the Conference of the International History, Philosophy, and Science Teaching Group, Rio de Janeiro, Brazil.

Justi, R., \& Mendonça, P. C. C. (2016). Discussion of the Controversy Concerning a Historical Event Among Preservice Teachers Contributions to Their Knowledge About Science, Their Argumentative Skills, and Reflections About Their Future Teaching Practices. Science E。 Education, 25(7-8), 795-822. doi:10.1007/s11191-016-9846-2

Laraia, R. B. (2001). Cultura: Um conceito antropológico. Rio de Janeiro: Jorge Zahar.

Leal, M. C. (2001). Como a química funciona? Quimica Nova na Escola, 14, 8-12.

Lederman, N. G. (2007). Nature of science: past, present, and future. In S. K. Abell \& N. G. Lederman (Eds.), Handbook of research Teducation (pp. 831-880). Mahwah: Lawrence Erlbaum Associates.

Lederman, N. G., Abd-Al-Khalick, F., Bell, R. L., \& Schwartz, R. S. (2002). Views of Nature of Science Questionnaire: Toward Valid and Meaningful Assessment of Learners' Conceptions of Nature of Science. Journal of Research in Science Teaching, 39(6), 487-521. doi:10.1002/tea.10034

Leroy, M. (Writer). (1943). Madame Curie. In. Estados Unidos da América.

Lopes, C. V. M. (2009). Modelos Atômicos no Início do Século XX: Da Física Clássica à Introdução da Teoria Quântica. Pontifícia Universidade Católica de São Paulo, São Paulo.

Lopes, C. V. M., \& Martins, R. A. (2009).J.J. Thomson e o Uso de Analogias para Explicar os Modelos Atômicos: O 'Pudim de Passas'nos Livros Texto Paper presented at the Encontro Nacional de Pesquisa em Educação em Ciências, Florianópolis. 
Marques, R. A. (2015). Formação de professores de ciências no contexto da História da Ciência. História da Ciência e Ensino: Construindo interfaces, 11, 1-17. Retrieved from https://revistas.pucsp.br/hcensino/article/view/23020

Martins, R. A. (1990). Como Becquerel não Descobriu a Radioatividade. Caderno Catarinense de Ensino de Física, 7, 27-45.

Martins, R. A. (1998). A Descoberta dos Raios X: O Primeiro Comunicado de Röntgen. Revista Brasileira de Ensino de Física 20(4), 373-391.

Martins, R. A. (2004). Hipóteses e Interpretação Experimental: A Conjetura de Poincaré e a Descoberta da Hiperfosforescência por Becquerel e Thompson. Ciência E̊ Educação, 10(3), 501-516. doi:10.1590/S151673132004000300013

Martins, R. A. (2006). Introdução: a História das Ciências e seus usos na educação. In C. C. Silva (Ed.), Estudos de História e Filosofia das Ciências: subsídios para aplicação no ensino (pp. 21-34). São Paulo: Livraria da Física.

Matthews, M. R. (2012). Changing the Focus: From Nature of Science to Features of Science. In Advances in Nature of Science Research (pp. 3-26). Dordrecht: Springer.

Maurines, L., \& Beaufils, D. (2012). Teaching the Nature of Science in Ohysics Courses: The Contribution of Classroom Historical Inquiries. Science E̊ Education, 22(6), 1443-1465. doi:10.1007/s11191-012-9495-z

Merriam, S. B. (1988). Case Study Research in Education - A Qualitative Approach. San Francisco and London.

Moura, C., Camel, T., \& Guerra, A. (2020). A Natureza da Ciência pelas Lentes do Currículo: Normatividade Curricular, Contextualização e os Sentidos de Ensinar sobre Ciências. Ensaio: Pesquisa e Educação em Ciências, 22, 1-27. doi:10.1590/1983-21172020210114

Noëlle, M. (Writer). (2016). Marie Curie: The Courage of Knowledge In. França.

Oki, M. C. M. (2009). Controvérsias sobre o atomismo no século XIX. Química Nova, 32(4), 1072-1082. doi:10.1590/ S0100-40422009000400043

Oki, M. C. M., \& Moradillo, E. F. (2008). O ensino de história da química: contribuindo para a compreensão da natureza da ciência. Ciência E̊ Educação, 14(1), 67-88. doi:10.1590/S1516-73132008000100005

Osborne, J., \& Dillon, J. (2010). How science works: what is the nature of scientific reasoning and what do we know about students' understanding? In J. Osborne \& J. Dillon (Eds.), Good Practice in Science Teaching: what research has to say (pp. 20-46). New York: Openup.

Pereira, B., \& Mohr, A. (2017). Origem e contornos da prática como componente curricular. In A. Mohr \& H. G. Wielewicki (Eds.), Prática como componente curricular: que novidade éessa 15 anos depois?(pp. 19-38). Florianópolis: NUP/CED/UFSC.

Porto, A. P. (2019). A história e Filosofia da Ciência no Ensino de Química: Em busca dos objetivos educacionais da atualidade. In P. F. L. Machado, W. L. P. Santos, \& O. A. Maldaner (Eds.), Ensino de Química em Foco (pp. 141-156). Ujuí: Editora Unijuí.

Pugliese, G. (2007). Um sobrevôo no "Caso Marie Curie": um experimento de antropologia, gênero e ciência. Revista de Antropologia, 50(1), 347-385. doi:10.1590/S0034-77012007000100009

Santos, M. A. R., Maia, P., \& Justi, R. (2020). Um Modelo de Ciências para Fundamentar a Introdução de Aspectos de Natureza da Ciência em Contextos de Ensino e para Analisar tais Contextos. Revista Brasileira De Pesquisa Em Educação Em Ciências, 20, 581-616. doi:10.28976/1984-2686rbpec2020u581616

Schnetzler, R. P. (2019). Apontamentos Sobre a História do Ensino de Química. In W. L. P. Santos, O. A. Maldaner, \& P. F. L. Machado (Eds.), Ensino de Química em Foco (2a ed.). Ujuí: Unijuí.

Shulman, L. S. (1986). Those Who Understand: Knowledge Growth in Teaching. Educational Research, 15(2), 4-14. doi:10.3102/0013189X015002004a

Vidal, P. H. O., Chelone, F. O., \& Porto, P. A. (2007). O Lavoisier que não está presente nos livros didáticos. Quimica Nova na Escola, 26, 29-32.

Yin, R. K. (2001). Estudo de Caso: Planejamento e métodos. Porto Alegre: Bookman. 


\section{NOTAS}

1 Utilizamos o termo sobre Ciências como sinônimo do termo Natureza da Ciência.

2 Todos os professores em formação inicial foram informados dos objetivos da pesquisa por meio do Termo de Consentimento Livre e Esclarecido e concordaram em dela participar.

3 Utilizamos nome fictício para preservar a identidade da participante.

4 Algo para o qual não podemos prever precisamente o resultado ou criar uma explicação.

5 Por exemplo, se ele é honesto e incorruptível em determinada situação.

6 Conjunto de crenças, hábitos, formas de vestir, pensar, agir, falar, comer, caminhar, rezar, entre outros, ou seja, é o que é passado, adquirido, aprendido, vivido e compartilhado entre os indivíduos (Laraia, 2001).

7 Advindas, segundo Santos et al. (2020), de posturas relacionadas à degradação do meio ambiente, ao racismo, ao feminismo, entre outras.

8 As ideias apresentadas por Ana estão em consonância com o recorte histórico apresentado em trabalhos como os de Martins (1990; 2004), que foram alguns dos textos usados para embasar o debate referente a esta atividade. Nesses textos o autor discute a veracidade duvidosa dos trabalhos de Becquerel, mas não necessariamente tudo que é apontado por Ana e por Martins se configura como uma verdade absoluta. Além disso, Ana pode ter escrito esse portfólio com os sentimentos aflorados, uma vez que, a PQFI assume, em outros momentos do seu portfólio, que era a primeira vez que estudava a fundo as questóes sociais que envolviam os trabalhos de Marie Curie.

\section{Marcondes Medeiros de Lima}

Licenciado em Química pela Universidade de Braślia.

E-mail:marcon_des@live.com

\section{Stefannie de Sá Ibraim}

Doutora em Educação pela Universidade Federal de Minas Gerais e membro do grupo de pesquisa REAGIR-Modelagem e Educação em Ciências. E-mail: stefannieibraim@ufmg.br

\section{Monique Santos}

Doutoranda em Educação pela Universidade Federal de Minas Gerais e membro do grupo de pesquisa REAGIR-Modelagem e Educação em Ciências. E-mail: moniquersqui@gmail.com

Contato da autora:

Stefannie de Sá Ibraim

Departamento de Química - Universidade Federal de Minas Gerais

Av. Antônio Carlos, no 6627

Belo Horizonte, MG | Brasil

CEP 31.270-901

Editor responsável:

Ana Carolina Araújo 